\title{
Obituary - Dr. George W. Bagby
}

\author{
Thomas R. Oxland ${ }^{1} \cdot$ Barrie Grant $^{2}$
}

Published online: 30 January 2017

(C) SICOT aisbl 2017

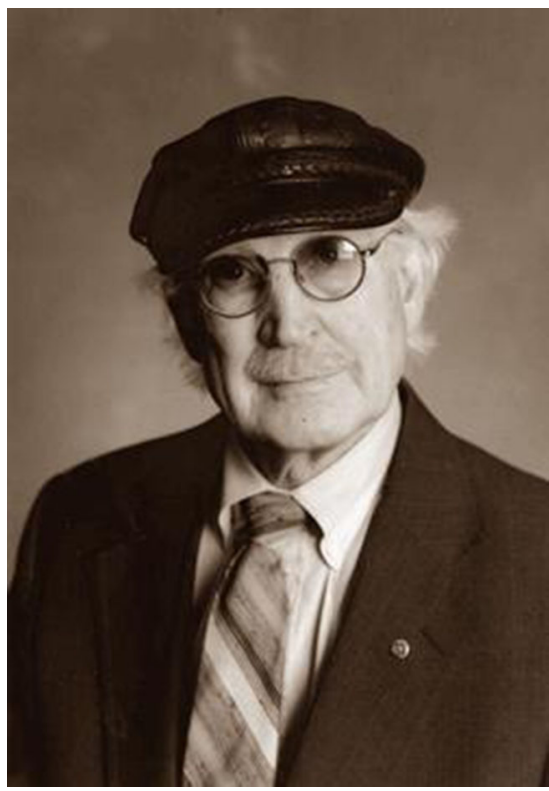

There is often no better time for reflection than when one of our most unique colleagues leaves us. Dr. George W. Bagby, from Spokane Washington USA, passed away in December 2016 at 93 years of age. Throughout his working years and into his 'retirement', Dr. Bagby, more commonly known as George by his friends and colleagues, exuded a keen pragmatic approach to addressing orthopaedic challenges, which

Thomas R. Oxland toxland@mail.ubc.ca

1 University of British Columbia, Vancouver, BC, Canada

2 Washington State University, Pullman, WA, USA

combined with his sincere interest in the lives of others, made him a most interesting and dedicated individual.

This article aims to highlight and acknowledge the seminal contributions made by Dr. Bagby to orthopaedic medicine. While he was an accomplished surgeon, it is his contributions to two important technologies, and his humanitarian efforts for which he will be remembered by most.

His first innovation came during his residency in Orthopaedic Surgery at the Mayo Clinic in the 1950s. He had returned to Rochester after spending time in the Korean War, taking care of injured soldiers. He thus was well aware of the challenges surrounding broken bones with traditional plates and screws. One day, while doing some home repairs on a metal screen door, George noticed that the adjacent sections of the screen door could be moved up or down by the offcentre insertion of a screw. This led him to wonder whether such an action could be applied to a metal plate for bone fractures, thereby invoking the potentially beneficial effects of compression across the fracture site. Dr. Bagby discussed this idea with colleagues at the Mayo Clinic, and conducted basic research in dogs that demonstrated the positive effects of a self-compressing bone plate on fracture healing in animals. $[1,2]$. This work led to Dr. Bagby's receiving a Master of Science in Orthopaedic Surgery from the Mayo Clinic. He extended this work to humans and published the human experience with the Bagby Bone Plate in 1968.

The second innovation came in the 1970's and 1980's in collaboration with veterinarian colleagues at Washington State University. Being located about $100 \mathrm{~km}$ from his new home in Spokane WA, George visited there in search of collaborators to help improve the bone plate. He soon found himself tackling the problem of Wobbler's Syndrome, a problem of cervical spine instability in horses. They began with the Cloward technique for interbody fusion in the cervical spine, but George eventually came up with the concept of a metallic 
cylinder with fenestrations as a means of stabilizing and fusing adjacent cervical vertebrae in the horse. As before, he began with methodical research studies to demonstrate the efficacy of the concept [3,5]. The Bagby Basket, as it was coined for horses, was extended to humans as the BAK device [4]. The technology was the first metallic interbody fusion technique and it led to a proliferation of similar methods in people over the subsequent decades.

In addition to his interests in technology and innovation, George cared deeply about orthopaedic care around the world, especially in disadvantaged countries. He was an active participant in Orthopaedics Overseas, frequently visiting both Vietnam and Bangladesh. This experience led him to build a new Orthopaedic Hospital in Nalta Bangladesh. The hospital was completed in 2000 and it has served over 7,000 in-patients with over 4,000 surgeries since that time.

In addition to being a visionary, Dr. Bagby's journey is one of collaboration, with Dr. Patrick Kelly on the selfcompressing bone plate, with Drs. Pam von Matthiesen (Wagner), Rick DeBowes, and Barrie Grant on the Bagby Basket, Dr. Stephen Kuslich on the BAK, and with Dr. Ruhal Haque on the Nalta Hospital, amongst many, many others.

George was a man of many interests and talents, whose intellect, curiosity, creativity, and gentle ways will be missed.
Respectfully submitted,

Thomas R. Oxland, PhD PEng

Professor of Orthopaedics and Mechanical Engineering

University of British Columbia

Barrie Grant, DVM

diplomate American College of Veterinary Surgery

Past Professor of Veterinary Medicine and Surgery

Washington State University

\section{References}

1. Bagby GW (1956) The effect of compression on the rate of fracture healing using a special plate. Master's Thesis, Mayo Clinic

2. Bagby GW, Janes JM (1958) The effect of compression on the rate of fracture healing using a special plate. Am J Surg 95:761-71

3. DeBowes RM, Grant BD, Bagby GW, Gallina AM, Sande RD, Ratzlaff MH (1984) Cervical vertebral interbody fusion in the horse: a comparative study of bovine xenografts and autografts supported by stainless steel baskets. Am J Vet Res 45(1):191-9

4. Kuslich SD, Ulstrom CL, Griffith SL, Ahern JW, Dowdle JD (1998) The Bagby and Kuslich method of lumbar interbody fusion. History, techniques, and 2-year follow-up results of a United States prospective, multicenter trial. Spine (Phila Pa 1976) 23(11):1267-78, discussion 1279

5. Wagner PC, Grant BD, Bagby GW (1979) Evaluation of cervical spinal fusion as a treatment in equine wobbler syndrome. Vet Surg $8: 84$ 